\title{
Kajian Etnobotani Serat Kulit Kayu Kepuak (Artocarpus elasticus Reinw. ex Blume) Pada Suku Dayak Desa'di Desa Kunyai Kecamatan Sungai Tebelian Kabupaten Sintang
}

\author{
Anci Veriyan ${ }^{1}$, Rafdinal ${ }^{1}$, Riza Linda \\ Program Studi Biologi, Fakultas MIPA, Universitas Tanjungpura \\ ${ }^{1}$ Prof. Dr. H. Hadari Nawawi, Pontianak, 78124 email korespondensi: Anciv15@gmail.com
}

\begin{abstract}
Artocarpus elasticus is one of the bark fiber-producing plants. Fiber plants have many uses, one of them is being used by Dayak Desa' Tribe to meet the needs of daily life in accordance with local wisdom. This study was carried out for two months from May to July 2019 with purposive sampling method. The result showed that the usage of bark fiber plants by Dayak Desa' community in Kunyai Village was varied. Based on the percentage of respondents' answers, bark fiber plants was used as crafts (100\%), clothes (88\%), ropes (60\%), building materials (36\%), and medicines (8\%). Dayak Desa' community knows and uses kepuak bark fiber well. The process of bark fiber was done by bark stripping, followed by bark flattening until it turns into sheets, and lastly submerged and dried.
\end{abstract}

Keywords: usage, bark fiber, Artocarpus elasticus, Dayak Desa' Tribe

\section{PENDAHULUAN}

Di Indonesia, keanekaragaman tumbuhan cukup tinggi, baik liar maupun budidaya, dimana hampir semua kelompok masyarakat sesuai karakter wilayah dan budaya memiliki ketergantungan pada berbagai tumbuhan, terutama untuk sumber penghasilan dan dimanfaatkan untuk menjadi barang yang berguna. Tercatat tidak kurang dari 50 jenis diantara 290 jenis tumbuhan penghasil serat digunakan sebagai bahan sandang oleh suku bangsa di Indonesia (Heyne, 1987). Sedangkan menurut buku PROSEA No. 17 (2003) diketahui terdapat 72 jenis tumbuhan penghasil serat utama, 128 jenis penghasil serat sekunder dan 619 jenis lainnya namun peranan utamanya adalah sebagai sumber bahan pangan, obat, bangunan, hias dan sebagainnya. Potensi yang dimiliki oleh tumbuhan penghasil serat belum sepenuhnya diketahui, dimanfaatkan atau bahkan dikembangkan salah satunya yaitu Artocarpus elasticus, masyarakat mengenalnya dengan nama daerah terap/kepuak. Jenis dari marga Artocarpus ini banyak tumbuh di daerah-daerah dataran rendah, namun ada pula yang tumbuh hingga $1500 \mathrm{~m}$ dpl.

Suku Dayak Desa' yang tinggal di Desa Kunyai terletak di Kecamatan Sungai Tebelian, Kabupaten Sintang, masyarakatnya masih menggunakan tumbuhan serat untuk dimanfaatkan, seperti salah satunya pemananfaatan serat kulit kayu kepuak. Bagian kulit batang pohon kepuak digunakan sebagai kerajinan dan pakaian oleh suku Dayak Desa'. Serat kulit pohon kepuak juga banyak digunakan sebagai bahan baku kerajinan, bahan tekstil, tali temali, kerajianan tangan, kertas dan sebagainya (Karnefi, 2005). Dalam penelitian Rahayu dan Hareda (2004), A. elasticus digunakan sebagai tumbuhan pelengkap upacara adat selain itu sebagai bahan tali temali dan anyaman. Dalam penelitian Astuti (2015), kulit kayu A. elasticus dimanfaatkan sebagai bahan pembuatan sepatu batik wanita. Penelitian Rahayu dan Sihotang (2013), kepuak ini termasuk salah satu tumbuhan penghasil serat kulit kayu yang digunakan sebagai bahan sandang.

Pemanfaatan tumbuhan serat kulit kayu biasanya diolah menjadi bahan mentah ataupun yang sudah diolah menjadi berbagai jenis kerajinan. Namun sebagian besar pemanfaatkan serat kulit kayu kepuak masih berbasis masyarakat lokal belum terdokumentasi dengan baik. Oleh karena itu diharapkan data etnobotani ini menjadi dokumentasi tentang pemanfaatan serat kulit kayu kepuak oleh suku bangsa di Indonesia, sehingga berkembang menjadi bahan baku khas daerah yang saat ini diminati, mendorong kreativitas masyarakat lokal untuk meningkatkan ekonomi dan pelestariannya dapat di kembangkan. 


\section{BAHAN DAN METODE}

\section{Waktu dan Tempat Penelitian}

Penelitian ini dilaksanakan dari bulan Mei hingga Juli 2019. di Desa Kunyai,Kecamatan Sungai Tebelian Kabupaten Sintang (Gambar 1).

\section{Prosedur Kerja}

Penelitian ini dilakukan di desa yang menjadi lokasi penelitian dengan menggunakan metode observasi (Sugiyono,2007). Tahapan pengumpulan data terhadap Suku Dayak Desa' di Desa Kunyai menggunakan metode purposive sampling. Responden yang ditunjuk ditetapkan dengan persyaratan seperti :

1. Sehat jasmani dan rohani

2. Responden berumur $>20$ tahun ke atas

3. Penduduk asli Dayak Desa' dan bertempat tinggal di Desa Kunyai

4. Memiliki pengetahuan dan memanfaatkan tumbuhan serat kulit kayu kepuak

5. Bersedia memberikan informasi mengenai tumbuhan kepuak di Desa Kunyai

Data primer diperoleh melalui teknik wawancara langsung dengan pendekatan ke masyarakat (Banilodu, 1998). Informasi diperoleh dengan wawancara semi terstruktur terhadap 25 orang responden, meliputi Kepala Dusun, pemuka masyarakat, Ketua RT serta masyarakat yang memiliki pengetahuan lokal mengenai pemanfaatan tumbuhan kepuak oleh masyarakat setempat. Wawancara dilakukan dengan daftar pertanyaan, selanjutnya hasil dari wawancara digunakan sebagai dasar dalam analisa kualitatif (Arikunto, 2006).

Seluruh data baik primer maupun sekunder dari berbagai sumber selanjutnya dianalisa secara kualitatif berbentuk deskriftif. Data kualitatif berbentuk deskriftif, yaitu analisis yang dilakukan dengan menguraikan atau menggambarkan rincian tentang situasi, kejadian, interaksi dan tingkah laku yang di amati dilapangan sebagaimana adanya (Nawawi, 1993)

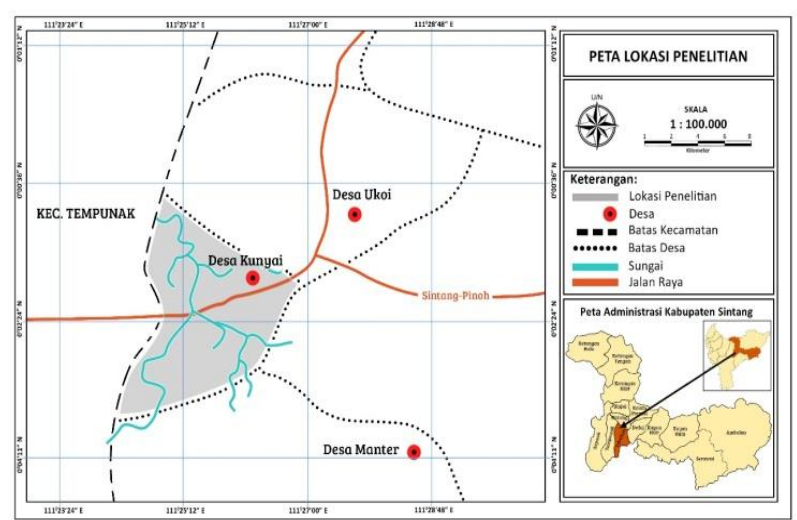

Gambar 1 Peta Lokasi Penelitian

\section{HASIL DAN PEMBAHASAN}

\section{Hasil}

Berdasarkan hasil wawancara dengan 25 responden Suku Dayak Desa' di Desa Kunyai, diperoleh persentase pemanfaatan serat kulit kayu yakni dalam pembuatan kerajinan (100\%), sedangkan sandang (88\%), tali-temali (60\%), bahan bangunan $(36 \%)$ dan paling sedikit pemanfaatannya yakni obat (8\%) (Gambar 2). Pemanfaatan kerajinan sangat tinggi karena semua responden mengolah serat kulit kayu kepuak sebagai kerajinan. Hasil kerajinan dan sandang diproduksi sesuai pesanan ataupun untuk kosumsi pribadi memiliki nilai jual cukup tinggi sehingga masyarakat lebih memfokuskan untuk memproduksi kerajinan dan sandang.

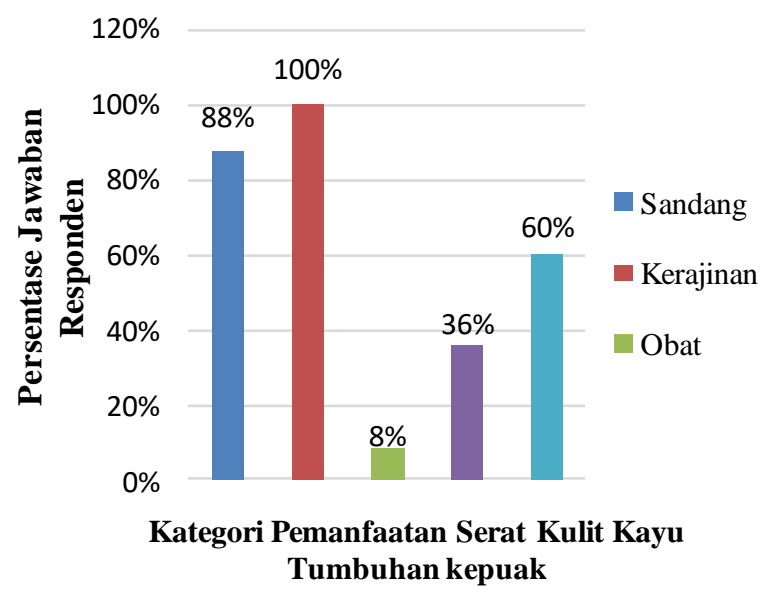

Gambar 2. Diagram Kategori Pemanfaatan Serat Kulit Tumbuhan Kepuak Oleh Masyarakat Suku Dayak Desa' Di Desa Kunyai 

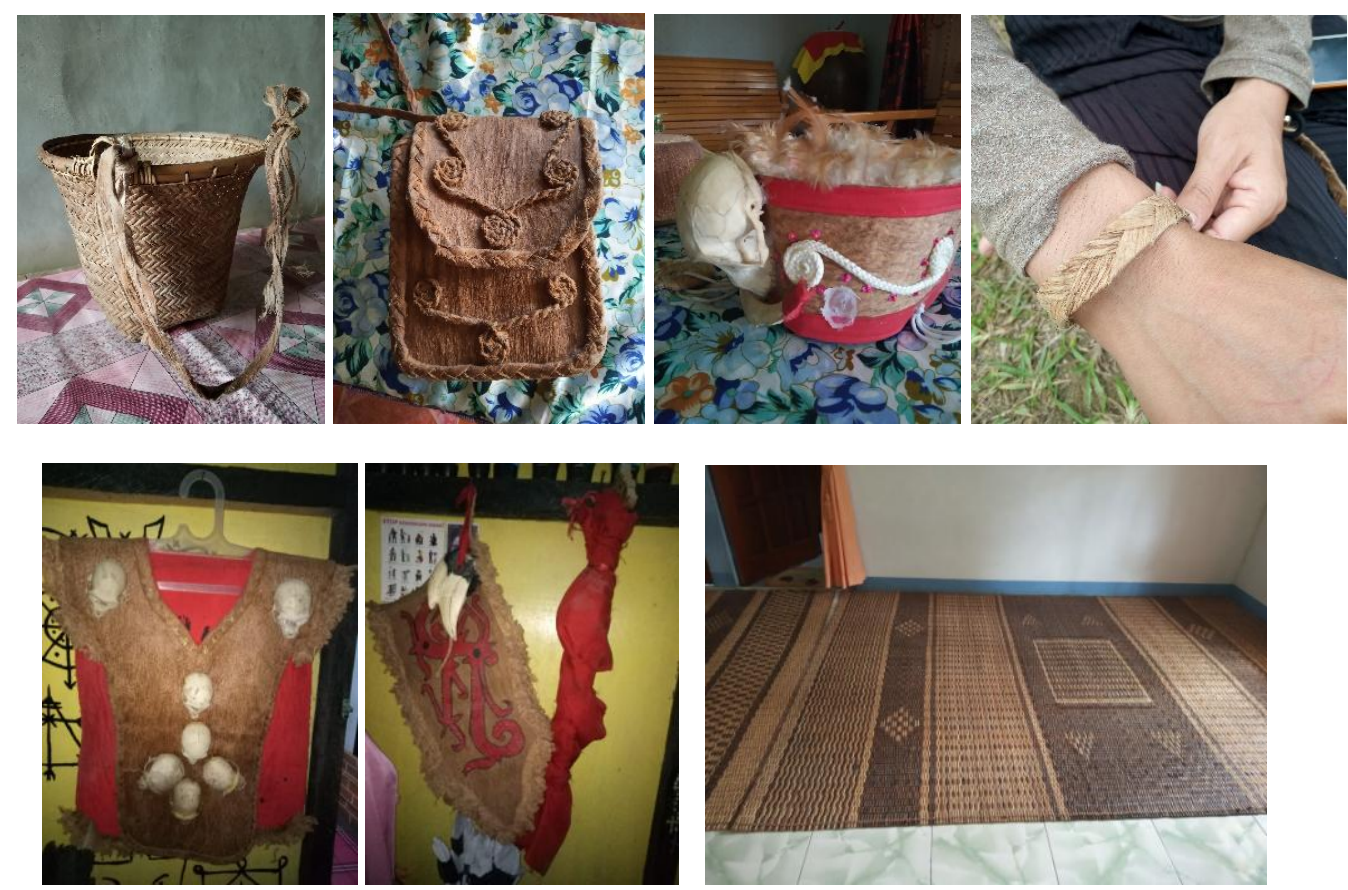

Gambar 3. Hasil Dari Pemanfaatan Tumbuhan Kepuak

\section{Pembahasan}

Mata pencaharian pokok masyarakat Suku Dayak Desa' di Desa Kunyai sebagian besar adalah bertani dan berkebun, sedangkan masyarakat memanfaatkan hasil dari serat kulit kayu tumbuhan kepuak (Artocarpus elasticus) hanya untuk menambah pendapatan.

Pemasaran dari hasil produksi serat kepuak ini hanya beroperasi di sekitar Desa Kunyai seperti di Dusun Rajang Begantung I, Dusun Rajang Begantung II dan Desa Suka jaya. Kurang luasnya pemasaran produksi tersebut dikarenakan masih minimnya permintaan masyarakat dari luar daerah Desa Kunyai terhadap hasil produksi dari pemanfaatan serat kepuak. Sebagian besar pohon kepuak yang dimanfaatkan masyarakat di Desa Kunyai tumbuh secara liar di ladang maupun di hutan Desa Kunyai. Jarak yang ditempuh cukup jauh dan sulit serta pengambilannya hanya saat menerima pesanan saja.

\section{Kerajinan}

Pada umumnya serat kulit kayu kepuak dimanfaatkan sebagai pernak pernik kerajinan oleh Suku Dayak Desa' di Desa Kunyai. Batang kayu muda dan tua dapat digunakan dalam pembuatan topi, tikar, gelang, tas dan tempat penyimpan handphone. Pengetahuan masyarakat Suku Dayak Desa' masih belum bervariasi seperti di daerah lainnya. Di daerah Yogyakarta dan jambi memanfaatkan kulit kayu kepuak untuk sarung bantal, taplak meja, dompet dan sepatu batik. Di daerah bali dimanfaatkan sebagai kanvas untuk melukis.

Kerajinan yang paling banyak dibuat oleh Suku Dayak Desa' yaitu topi. Pembuatan topi sangat mudah dilakukan, pertama dilakukan proses pembuatan lembaran serat terlebih dahulu dengan langkah penebangan pohon, selanjutnya batang pohon di bersihkan dari rantingnya dan dipukulpukul agar kulit kayu terlepas dari batangnya, selanjutnya kulit kayu dilakukan pengelupasan dan dipukul-pukul hingga pipih dan menjadi lembaran tipis. Selanjutnya direndam selama 1 hari, setelah direndam selanjutnya dijemur selama 2-3 hari. Setelah kering lembaran tersebut di setrika agar rapi dan terjaga warna khasnya.

Dalam pembuatan topi, tas dan tempat handphone hampir sama cara pembuatannya, lembaran serat yang sudah jadi dibuat pola. Pada pembuatan topi dasar pola yang dibuat menyerupai topi koboi (bulat). Selanjutnya bagian pola digunting sesuai ukuran yang ditentukan dan menyesuaikan lingkar kepala. Pola tersebut di lem dengan menggunakan lem khusus. Untuk hasil yang lebih keras dan berwarna biasanya digunakan cat vernis supaya lebih mengkilap. Dapat juga diberi pernak-pernik yang terbuat dari kerangka hewan ataupun taring hewan. Bagian dalam dapat juga diberi alas kain.

Pengolahan kerajinan tas dan tempat handphone sama halnya dengan pembuatan topi, dari bahan 
lembaran serat tersebut di bentuk sesuai pola yang diinginkan, biasanya membentuk persegi. Pembuatan pola, dimulai dari membuat pola sisi depan, belakang dan penutup. Lembaran digunting sesuai pola dan di satukan pola tersebut dengan menggunakan lem khusus. Tas dan tempat handphone yang sudah terbentuk kemudian diberi pelengkap seperti tali yang disimpul ataupun tali yang dikepang, tali tersebut terbuat kulit kayu juga. Untuk membuat tampilan lebih cantik dan bagus, tas dan tempat handphone di olesi cat vernis. Selanjutnya dalam pembuatan tikar, lembaran yang digunakan dipotong dengan lebar sekitar 5-10 cm, lalu di anyam dengan bahan lainnya seperti rotan

\section{Bahan Bangunan}

Serat kulit kayu kepuak dapat dimanfaatkan sebagai bahan bangunan yakni bagian dinding bangunan. Sebelum berkembangnya tahun ke tahun, zaman dahulu dinding rumah-rumah menggunakan serat kulit kayu kepuak. Pada Suku Dayak Desa' serat kulit kayu tersebut digunakan untuk dinding rumah penyimpanan padi di lading. Penggunaan dinding serat kulit kayu pada zaman sekarang kurang dimanfaatkan, karena perkembangan bahan bagunan yang sudah modern seperti adanya semen ataupun papan. Dalam pemanfaatan dinding rumah, batang tanaman bagian bawah yang digunakan untuk di ambil seratnya.

Proses pembuatan dinding rumah yaitu pertama dilakukan penebangan, kulit kayu yang digunakan pada umumnya di atas 5 tahun dan harus tegak lurus. Kemudian dibersihkan dari rantingnya, dan batang kayu dipukul pukul agar kulit kayu mudah terpisah dari batangnya. Selanjutnya dilakukan pengelupasan dan dipukul pukul secara kasar. Dijemur hingga kering, penjemuran ini di lakukan sekitar 3-5 hari, dan proses terakhir, bahan serat kayu tersebut di susun menjadi dinding pada kerangka dinding rumah yang sudah di buat, sehingga menutupi sekeliling rumah.

\section{Sandang}

Serat kulit kayu kepuak dimanfaatkan sebagai bahan sandang seperti pakaian adat dayak yakni king baba (rompi) dan cawat (penutup celana). Sebagai bahan sandang, pemanfaatan serat kulit kayu di Desa Kunyai tidak setiap saat digunakan, hanya pada waktu waktu tertentu saja seperti pada acara pernikahan, pertemuan adat dan gawai dayak. Pakaian dari serat kulit kayu zaman sekarang kurang diminati karena banyak masyarakat sudah menggunakan pakaian dari bahan kain. Pada zaman dahulu kulit kayu digunakan secara tradisional oleh suku aborigin dalam kehidupan sehari hari seperti selimut, kaos, celana dalam, dan jaket (Prosea, 2003)

Pada pembuatan sandang terlebih dahulu harus menyiapkan serat kayu yang telah diolah menjadi lembaran serat, proses pembuatan bahan lembaran serat sama seperti yang dilakukan pada pembuatan lembaran serat kerajinan. Selanjutnya lembaran tersebut di gambar sesuai pola yang diinginkan, lalu digunting dan menjadi pola setengah jadi misalnya pada rompi. Rompi yang setengah jadi diberi kain untuk dalamnya lalu dijait dan dirapikan. Sama halnya dengan cawat, pola bahan yang sudah di gambar, digunting selanjutnya di beri kain dan dijait rapi. Selanjutnya agar rompi terlihat cantik dan menarik ditambah pernak-pernik seperti tengkorak hewan ataupun dilukis dengan motif dayak. Umumnya cawat hanya dilukis motif dayak menggunakan cat minyak.

\section{Obat}

Serat kulit kayu kepuak dapat dimanfaatkan sebagai obat. Zaman dahulu pada Suku Dayak Desa' memanfaatkan serat kulit kayu kepuak untuk obat sakit perut dengan cara dimakan langsung. Bagian batang yang muda yang digunakan sebagai obat. Namun zaman sekarang sudah kurang diminati bahkan tidak pernah lagi digunakan sebagai obat karena kebanyakan masyarakat menggunakan obat generik, obat nama dagang (branded drug), obat herbal yang modern untuk dikosumsi. Menurut Rahayu dan Sihotang (2013), Kulit batang kepuak berkhasiat sebagai obat sakit perut dan getahnya sebagai obat sakit mencret. Untuk obat sakit perut dipakai kulit batang kepuak, dipukul-pukul lalu digunakan sebagai sabuk perut.

Pada hasil wawancara, pemanfaatan serat kulit kayu dilakukan dengan cara, bagian pucuk batang dipotong selanjutnya di kuliti dan dibersihkan. Bagian yang sudah dikuliti tersebut di makan secara mentah. Menurut responden hal tersebut biasanya dilakukan oleh orang tua zaman dulu jika sakit perut.

\section{Tali Temali}

Berdasarkan hasil wawancara, serat kulit kayu kepuak dapat digunakan untuk tali temali. Diperlukan batang muda untuk pembuatan tali temali. Pada suku Dayak Desa' memanfaatkan serat kulit kayu ini untuk tali takin, tali ayunan dan tali pengikat parang. Dalam penelitian Rahayu dan Sihotang (2013), menjelaskan Artocarpus elasticus 
digunakan sebagai bahan tali-temali, "tambanan" (dari batang muda dan "nyawur" (kulit batang tua).

Pembuatan tali-menali dilakukan dengan memilih pohon yang tidak terlalu besar diameternya, sekitar $10 \mathrm{~cm}$. Jika menggunakan batang muda, sangat mudah untuk mengulitinya dengan cara di ikat kepohon dan di tarik, setelah itu dipukul-pukul hingga menjadi pipih dan selanjutnya di jemur 1-2 hari

\section{DAFTAR PUSTAKA}

Arikunto, S., 2006, Prosedur Penelitian Suatu Pendekatan Praktek, edisi revisi VI. PT. Rineka Cipta, Jakarta

Astuti, D, 2015, Pemanfaatan Kulit Kayu Lantung Sebagai Bahan Pembuatan Sepatu Batik Wanita, Skripsi, Universitas Negeri Yogyakarta, Yogyakarta

Banilodu, 1998, Implikasi Etnobotani Kuantitatif dalam Kaitannya dengan Konservasi Gunung Mutis Timor, IPB, Bogor

Heyne, 1987, Tumbuhan Berguna Indonesia, Terjemahan Badan Litbang Kehutanan, Yayasan Sarana Wanajaya, Jakarta

Karnefi, V Sozi, 2005, Uji kekuatan Kayu terap dengan metode Tarik kearah lebar panjang, Jurnal Gradien, vol. 1, no. 1, hal 20-22

Nawawi, H., 1993, Metode Penelitian Bidang Ilmu Sosial, Gadjah Mada University Press, Yogyakarta

PROSEA, 2003, Fibre Plants, in Plant Resource of South-East Asia no.17, Prosea Network office, Bogor, Indonesia

Rahayu, M dan K. Harada, 2004, Peran tumbuhan dalam kehidupan masyarakat lokal di Taman Nasional Gunung Halimun, Jawa Barat, Berita Biologi,vol. 7, no. 1, hal 17- 23

Rahayu, M \& Sihotang, F,B,L, 2013. Serat kulit kayu bahan sandang: keanekaragaman jenis dan prospeknya di Indonesia,Berita biologi, Vol. 12 no. 3

Sugiyono, 2016, Metode Penelitian Pendidikan Pendekatan Kuantitatif, Kualitatif, dan $R \& D$, Edisi 23, Alfabeta, Bandung 